\title{
Locomotive Syndrome Associated With Daily Moderate to Vigorous Physical Activity in Community-dwelling Older Adults: A Cross-sectional Analysis
}

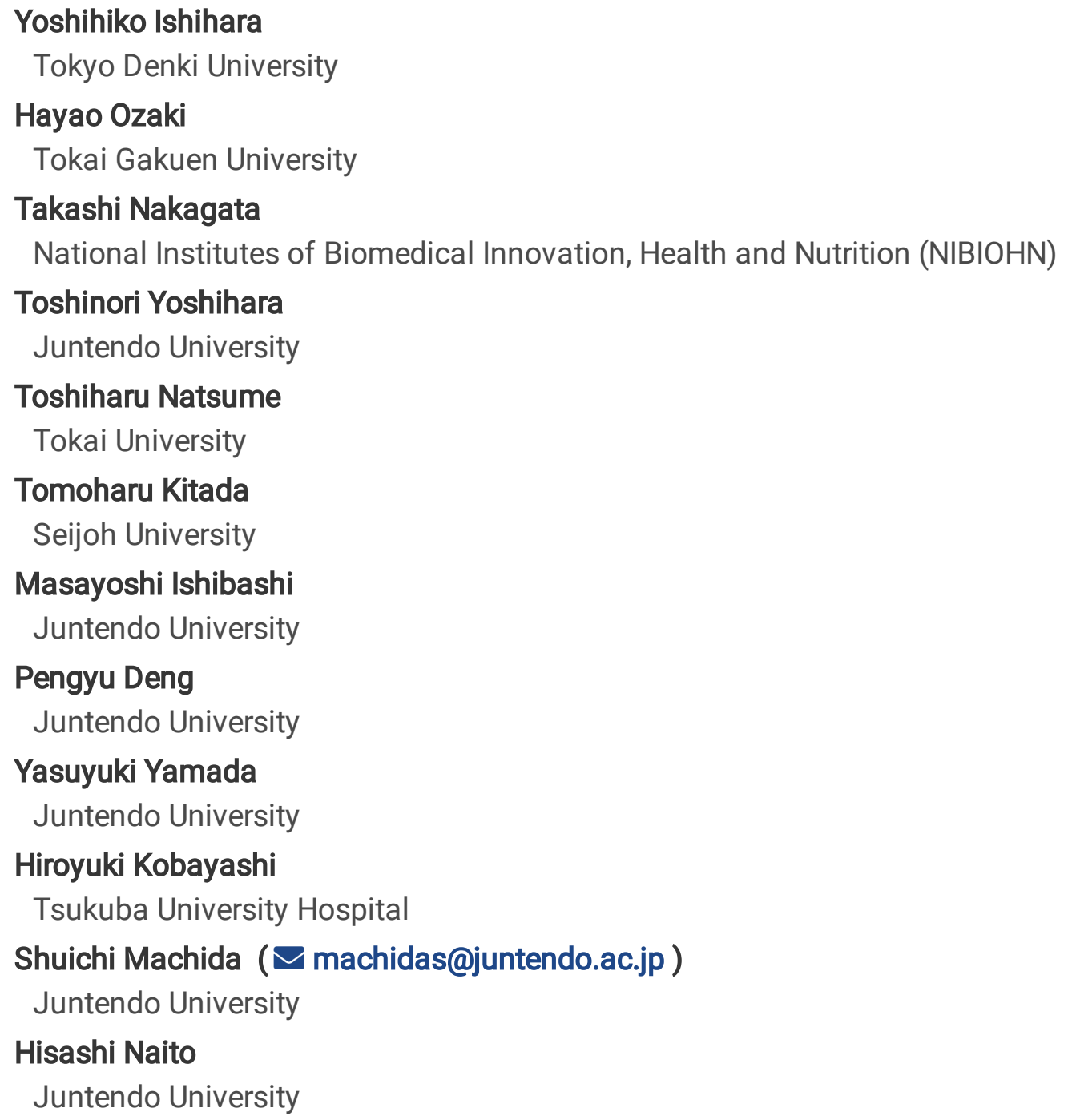

\section{Research Article}

Keywords: Locomotive syndrome, daily physical activity, moderate to vigorous physical activity, three-axis accelerometer, leg muscle strength, Aging

Posted Date: January 5th, 2022

DOl: https://doi.org/10.21203/rs.3.rs-1203575/v1 
License: (a) (1) This work is licensed under a Creative Commons Attribution 4.0 International License. Read Full License 


\section{Abstract}

Background: Locomotive syndrome (LS) is associated with weakness and loss of function in the musculoskeletal organs. To evaluate the association between LS and daily physical activities (PA) in community-dwelling older adults using a three-axis accelerometer.

Methods: This cross-sectional study included healthy 80 older adults (40 men and 40 women; age: 60-79 years). Three functional tests, the two-step test, the stand-up test, and the 25-question geriatric locomotive function scale (GLFS) were used to assess the risk of LS. Maximal isometric muscle strengths of the knee extensors were examined, and the weight bearing index (knee extension strength/body weight) was calculated. Habitual daily PA was evaluated using a three-axis wrist accelerometer.

Results: Of the 80 participants, 41 (51.3\%) fulfilled the diagnostic criteria for LS (including a two-step test score < 1.3 , difficulty with one-leg standing from $40 \mathrm{~cm}$ in the stand-up test, and a 25-question GLFS score $\geq 7$ ) We found that step count and time spent performing moderate to vigorous PA (MVPA) were significantly higher in women participants without LS compared to those with LS ( $p=0.01)$; no significant difference was found in men. Logistic regression analyses indicated a longer time spent performing MVPA ( $>47.26 \mathrm{~min} /$ day) was associated with a lower risk of LS compared to only performing for $21.11 \mathrm{~min} /$ day.

Conclusions: Our data showed that daily MVPA using a three-axis accelerometer was associated with LS in community-dwelling older adult women, but not in men.

\section{Background}

Aging is associated with a decline in physical function, particularly, in balancing, climbing stairs, and standing from a sitting position [1-4]. There is a decrease in the ability to perform activities of daily living and an increase in the risk of falls and fractures leading to reduced independency $[5,6]$. Japan can be considered a "super aged society" since one out of every four Japanese is an older adult [7]. Therefore, a comprehensive and evidence-based prevention strategy for musculoskeletal diseases is urgently required. In 2007, the Japanese Orthopaedic Association (JOA) proposed the term "locomotive syndrome" (LS), which causes difficulties in the ability to perform motor and physical functions essential to daily life [7]. LS is caused by the weakening and loss of musculoskeletal tissues, such as bone, joint, and muscle [9]. In 2013, the JOA proposed the two-step test, stand-up test, and 25question geriatric locomotive function scale (GLFS-25) for assessing LS [7]. Previous evidences have shown that the diagnosis of LS is ascertained using these three tests which are based on age-dependent changes in adults without specific mobility disorders aged 20-91 [6, 8]. Moreover, Ogata et al. [8] found that this battery of tests is an effective screening tool in determining the risk of LS in adults. Recently, Imagama et al. [9] suggested a stronger correlation between LS and musculoskeletal factors compared to frailty, in the development of poor physical and mental quality of life (QOL). These factors should be evaluated early, especially in independent older adults, to maintain activities of daily living (ADL) and QOL. Therefore, LS risk factors include decreased levels of daily physical activity (PA) and ADL that occur with aging. To maintain the older adults's ADL and QOL, specific target values for daily PA should be provided in combination with LS screening. However, the quantity and quality of daily PA associated with the components of LS have yet to be clearly defined.

The intensity of PA shows a positive association with various components of physical fitness and function, as well as negative associations with the incidence of diseases that cause morbidity and mortality in the older adults [1012]. In particular, an intensity above 3 metabolic equivalents [3METs; moderate to vigorous PA (MVPA)] is essential 
for successful ageing [13]. Previous sensor-based PA studies have demonstrated that the daily step count and MVPA were associated with musculoskeletal tissue health, calcaneal health, and frailty status $[3,5,12,14,15]$. Park et al. [14] suggested that older adults aged 65-84 years who walked at least 7,000-8,000 steps/day and/or spent 15-20 min/day performing MVPA using a uniaxial accelerometer were likely to develop muscle mass above the sarcopenia threshold. Imagawa et al. [9] showed that gait ability (10 m gait time and timed-up and go test) and muscle strength (grip and back muscle strength) were lower among older adults with LS compared to those without LS. Thus, the amount and intensity of daily PA (i.e., step counts and MVPA) is likely to be important for the maintenance of ADL, QOL and prevention of LS. Since walking is the main form of spontaneous PA for most older adults, the average daily step count and intensity of daily PA using an accelerometer offers a promising objective indicator of daily PA. To our knowledge, previous studies have used physical functioning tests for the objective assessment of LS; however, specific, everyday PA characteristics using a three-axis accelerometer have not been quantified. Among community-dwelling older adults, the association between the presence of LS and habitual daily PA characteristics is unclear. Wearable sensors have the benefits of objectivity, portability, and affordability, making these devices useful for LS assessment in the home and community.

Therefore, this study aimed to evaluate the association between LS and daily PA in community-dwelling older adults using a three-axis accelerometer. The primary outcomes were to show the mean value of the daily step counts, and activity time by exercise intensities in LS and non-LS.

\section{Methods}

\section{Participants}

We performed a cross-sectional analysis between May 2015 and November 2016. In total, 143 healthy communitydwelling individuals (ages: 40-85 years) were included in this study. Of the 143 subjects, 63 were excluded because they had a history of regular sports (tennis and cycling), resistance training (body weight, tube and/or machine), participation in exercise intervention experiments, or were under 60 or over 80 years old. A total of 80 healthy, community-dwelling older adults (40 men and 40 women; age: 60-79 years) were included in the present study. The participants had not history of resistance training, cycling, and other sports activity (i.e., tennis, golf, cycling etc.) for at least 1 year prior to the start of the study. We excluded individuals who were unable to follow our instructions and those with chronic orthopedic conditions or any health or medical condition that limited the ability to undertake light-to-moderate walking. In addition, the participants completed a self-report questionnaire regarding medical history and comorbid conditions. All participants were informed of the study methods, procedures, and risks, and each signed an informed consent document before participating in the study. This study was approved by the Ethics Committee of the Juntendo University (Approval Number: 26-75).

\section{LS tests}

To screen the presence of LS, the participants were tasked to perform the two-step test and stand-up test as functional tests [8], and were asked to answer the GLFS-25 questionnaire [16]. The participants stood with the toes of both feet behind a starting line. They were instructed to take two long steps (as long as possible) and to align both feet. The length of the two steps from the starting line to the tips of the toes was measured. The two-step test score was calculated using the following formula: length of the two steps $(\mathrm{cm}) /$ height $(\mathrm{cm})$. The participants were also instructed to stand using one or both legs from a specific height. Seats were placed at the following heights: $40,30,20$, and $10 \mathrm{~cm}$. The participants stood up from each seat (in descending height order) using both legs, and 
then using each leg separately. A participant passed the test at the specified height if they were able to stand up without leaning back to gain momentum and maintain the posture for $3 \mathrm{sec}$. The GLFS-25 is a self-administered, comprehensive questionnaire consisting of 25 items, that assessed the patient's pain (4), ADL (16), social function (3), and mental health status (2) during the last month. These items are graded using a five-point scale from 0 (no impairment) to 4 points (severe impairment). The scores are added to produce a total score (minimum $=0$, maximum $=100$ ). A higher score is associated with worse locomotive function. Our previous study [17] indicated that the measured variables from the stand-up test, two-step test, and GLFS-25 have enough validity and reliability, with the intra-class correlation coefficients being $0.87,0.93$, and 0.76 and Cronbach's a being $0.93,0.95$, and 0.88 , respectively. These tests were used to assess declines in mobility of each participant.

The JOA has proposed clinical decision limits for these tests in the assessment of LS [7]. According to the results of the LS test, the participants were classified as having LS when a participant met one or more of the following criteria: (1) two-step test score $<1.3,(2)$ difficulty in standing from a seat at a height of $40 \mathrm{~cm}$ using one leg in the stand-up test (either leg), and (3) GLFS score $\geq 7$ [7]. All other participants were placed in the non-LS group. In this study, we focused on the stage 1 of JOA definition of LS considered as LS group (including stage 1 and 2; n=35 and 6), and the independent values were compared between the LS and non-LS groups.

\section{Habitual daily PA}

We measured daily PA using a three-axis accelerometer (UW-301, A\&D, Toshima, Tokyo). The participants were instructed to wear the accelerometer around the wrist continuously for 9-14 days except during dressing and bathing. Accelerometer readings recorded for a minimum of 7 continuous days, excluding the distribution and collection days, were considered in the study; days wherein the accelerometer was not worn for more than 2 hours were excluded [18]. Activities were classified into five levels of intensity, according to the accelerometer data: 1 , resting (<1.1 METs); 2, sitting behavior (1.1-1.4 METs); 3, standing behavior (1.5-2.9 METs); 4, moderate PA (3.05.9 METs); and 5 , vigorous PA ( $\geqq 6$ METs). The sum of the time spent in moderate and vigorous PA ( 3 METs) was calculated and defined as MVPA. Additionally, the sum of the time spent in resting and sitting behaviors $(<1.5$ METs) was calculated and defined as RSB.

\section{Anthropometrics and body composition}

Anthropometric measurements included height $(\mathrm{cm})$, weight $(\mathrm{kg})$, and body mass index (BMI, weight [kg] / height

$\left.\left[\mathrm{m}^{2}\right]\right)$. Body composition measurements included body fat, muscle mass, and waist-to-hip ratio; these were estimated by bioelectrical impedance analysis (BIA) using a body composition analyzer (InBody 730, Biospace Co. Ltd, Seoul, Korea). Appendicular skeletal lean mass (ALM) was calculated as the sum of the muscle mass of the arms and legs [19]. We calculated the skeletal muscle index (SMI) as follows: SMI = ALM/height ${ }^{2}$.

\section{Maximal isometric strengths of leg muscle}

The maximal voluntary isometric strength of the knee extensors was determined using a dynamometer (Takei, Tokyo, Japan). Each participant was seated on a chair with the hip joint angle at $90^{\circ}$ flexion $\left(0^{\circ}=\right.$ full hip extension). Prior to the test, several warm-up contractions (2-3 submaximal contractions and 1-2 near-maximal contractions) were performed. They were instructed to perform maximum isometric knee extensions two or three times. The best recorded value was used as the representative, and the weight bearing index (knee strength/ body weight; KE-WBI) was calculated. However, five participants were unable to perform the test due to high blood 
pressure which was measured before conducting the test. With regard to knee extension strength, the test-retest (inter-session) reliabilities using ICC, SEM, and minimal difference were 0.945, $3.41 \mathrm{~kg}$, and $9.45 \mathrm{~kg}$, respectively.

\section{Statistical analysis}

Data are presented as means \pm standard deviations (SD). Differences between the non-LS and LS groups were determined using the unpaired Student's t-test. Relationships among the three LS parameters, daily PA, and anthropometric and body composition measurements were examined using Pearson's product-moment correlation analysis. Finally, this study conducted binomial logistic regression analyses (LRA) to examine the statistical relationships between daily PA and category of LS adjusting for sex difference and age. For this analysis, the continuous variables of daily PA were divided into quartile categories (Table 4). All analyses were performed using SPSS software (ver. 24; SPSS Inc., USA). Statistical significance was set at $p<0.05$.

\section{Results}

Overall, the prevalence of LS was 51.3\% (41/80; men, 20; women, 21). The characteristics of the non-LS and LS participants are presented in Table 1. Among the participants, the proportions which obtained two-step test scores of $<1.3$, difficulty in standing from a seat at a height of $40 \mathrm{~cm}$ using one leg in the stand-up test, and GLFS-25 scores $\geqq 7$ were $12.5 \%, 36.3 \%$, and $21.3 \%$, respectively. The body fat percentage of women was significantly higher among non-LS participants compared to LS participants; however, no difference was observed in men. Men non-LS participants were significantly taller and heavier compared to LS participants. KE-WBI of women and men was significantly higher among non-LS participants than among LS participants (Table 1). 
Table 1

Characteristics of the participants without locomotive syndrome (non-LS) and those with locomotive syndrome (LS).

\begin{tabular}{|c|c|c|c|c|c|c|}
\hline & Men & & & Women & & \\
\hline Variables & $\begin{array}{l}\text { Total } \\
(n=40)\end{array}$ & $\begin{array}{l}\text { non-LS } \\
(n=20)\end{array}$ & $\operatorname{LS}(n=20)$ & $\begin{array}{l}\text { Total } \\
(n=40)\end{array}$ & $\begin{array}{l}\text { non-LS } \\
(n=19)\end{array}$ & $\operatorname{LS}(n=21)$ \\
\hline Age (years) & $69.9 \pm 4.8$ & $68.6 \pm 3.4$ & $71.2 \pm 5.6$ & $68.7 \pm 4.5$ & $66.9 \pm 4.0$ & $\begin{array}{l}70.3 \pm \\
4.3^{\dagger+}\end{array}$ \\
\hline Height (cm) & $\begin{array}{l}165.8 \pm \\
6.4\end{array}$ & $163.4 \pm 5.7$ & $\begin{array}{l}168.2 \pm \\
6.3^{\dagger+}\end{array}$ & $\begin{array}{l}152.9 \pm \\
5.5^{\star \star}\end{array}$ & $152.8 \pm 3.5$ & $153.0 \pm 7.0$ \\
\hline Weight (kg) & $65.2 \pm 9.3$ & $61.7 \pm 8.5$ & $\begin{array}{l}68.7 \pm \\
8.9^{\dagger+}\end{array}$ & $\begin{array}{l}52.7 \pm \\
7.3^{\star \star}\end{array}$ & $51.0 \pm 7.1$ & $54.1 \pm 7.3$ \\
\hline BMI $\left(\mathrm{kg} / \mathrm{m}^{2}\right)$ & $23.7 \pm 2.5$ & $23.1 \pm 2.6$ & $24.2 \pm 2.4$ & $22.5 \pm 2.8$ & $21.9 \pm 2.9$ & $23.1 \pm 2.7$ \\
\hline Body fat (\%) & $23.5 \pm 5.4$ & $22.0 \pm 4.8$ & $25.0 \pm 5.5$ & $\begin{array}{l}31.7 \pm \\
5.9 * \star\end{array}$ & $29.5 \pm 6.3$ & $33.6 \pm 5.0^{\dagger}$ \\
\hline Muscle mass (kg) & $27.3 \pm 3.2$ & $26.4 \pm 2.9$ & $28.2 \pm 3.4$ & $\begin{array}{l}18.9 \pm \\
2.1 * \star\end{array}$ & $19.0 \pm 1.9$ & $18.8 \pm 2.3$ \\
\hline $\mathrm{SMI}\left(\mathrm{kg} / \mathrm{m}^{2}\right)$ & $\begin{array}{l}7.56 \pm \\
0.61\end{array}$ & $7.43 \pm 0.67$ & $7.70 \pm 0.52$ & $\begin{array}{l}6.02 \pm \\
0.59 * \star\end{array}$ & $6.01 \pm 0.57$ & $6.02 \pm 0.62$ \\
\hline Leg-SMI $\left(\mathrm{kg} / \mathrm{m}^{2}\right)$ & $\begin{array}{l}5.64 \pm \\
0.73\end{array}$ & $5.53 \pm 0.52$ & $5.76 \pm 0.41$ & $\begin{array}{l}4.65 \pm \\
0.43^{\star \star}\end{array}$ & $4.62 \pm 0.38$ & $4.68 \pm 0.47$ \\
\hline $\begin{array}{l}\text { Femoral } \\
\text { circumference }\end{array}$ & $47.7 \pm 3.1$ & $47.3 \pm 3.2$ & $48.1 \pm 2.9$ & $45.8 \pm 4.7$ & $46.7 \pm 4.0$ & $45.0 \pm 5.2$ \\
\hline $\begin{array}{l}\mathrm{KE}-W B \mathrm{l}(\mathrm{kg} / \mathrm{kg} \\
\text { weight) }\end{array}$ & $\begin{array}{l}0.74 \pm \\
0.17\end{array}$ & $0.82 \pm 0.18$ & $\begin{array}{l}0.66 \pm \\
0.13^{+\dagger}\end{array}$ & $0.64 \pm 0.13$ & $0.70 \pm 0.13$ & $\begin{array}{l}0.60 \pm \\
0.11^{\dagger}\end{array}$ \\
\hline \multicolumn{7}{|l|}{ LS tests } \\
\hline $\begin{array}{l}\text { Stand-up test } \\
\text { (score) }\end{array}$ & $\begin{array}{l}4.53 \pm \\
1.18\end{array}$ & $5.30 \pm 0.73$ & $\begin{array}{l}3.75 \pm \\
1.02^{+\dagger}\end{array}$ & $4.65 \pm 1.08$ & $5.37 \pm 0.60$ & $\begin{array}{l}4.00 \pm \\
1.00^{\dagger \dagger}\end{array}$ \\
\hline $\begin{array}{l}\text { Two-step test } \\
\text { (score) }\end{array}$ & $\begin{array}{l}1.44 \pm \\
0.11\end{array}$ & $1.48 \pm 0.11$ & $\begin{array}{l}1.40 \pm \\
0.10^{\dagger \dagger}\end{array}$ & $1.36 \pm 0.12$ & $1.43 \pm 0.09$ & $\begin{array}{l}1.31 \pm \\
0.12^{\dagger \dagger}\end{array}$ \\
\hline GLFS-25 (score) & $\begin{array}{l}3.90 \pm \\
4.31\end{array}$ & $2.40 \pm 1.98$ & $\begin{array}{l}5.40 \pm \\
5.43^{\dagger}\end{array}$ & $4.28 \pm 3.73$ & $2.37 \pm 1.83$ & $\begin{array}{l}6.00 \pm \\
4.18^{+\dagger}\end{array}$ \\
\hline
\end{tabular}

Means \pm standard deviations, ${ }^{* *} p<0.01$, vs. Men. ${ }^{\dagger} p<0.05,{ }^{\dagger \dagger} p<0.01$, vs. non-LS., BMI: body mass index, SMI: skeletal muscle mass index, Leg-SMI: leg muscle mass index, KE-WBI: knee extension strength/body weight.

No significant differences were observed between sexes in the mean step count and time spent performing MVPA (Table 2). For women, the mean step count and time spent performing MVPA were significantly higher among nonLS participants than among LS participants (Table 2). For men, there was no significant differences were observed for daily PA (Table 2). 
Table 2

Daily PA of the participants without locomotive syndrome (non-LS) and those with locomotive syndrome (LS).

\begin{tabular}{|c|c|c|c|c|c|c|}
\hline \multirow[t]{2}{*}{ Daily PA Variables } & \multicolumn{3}{|c|}{ Men } & \multicolumn{3}{|c|}{ Women } \\
\hline & $\begin{array}{l}\text { Total } \\
(n=40)\end{array}$ & $\begin{array}{l}\text { non-LS } \\
(n=20)\end{array}$ & LS $(n=20)$ & Total $(n=40)$ & $\begin{array}{l}\text { non-LS } \\
(n=19)\end{array}$ & $\operatorname{LS}(n=21)$ \\
\hline Step count (steps/day) & $\begin{array}{l}6807 \pm \\
3410\end{array}$ & $\begin{array}{l}7258 \pm \\
3881\end{array}$ & $\begin{array}{l}6356 \pm \\
2895\end{array}$ & $\begin{array}{l}5819 \pm \\
2519\end{array}$ & $\begin{array}{l}6829 \pm \\
2390\end{array}$ & $\begin{array}{l}4905 \pm \\
2321^{\dagger+}\end{array}$ \\
\hline $\begin{array}{l}\mathrm{RSB} ;<1.5 \mathrm{METs} \\
\text { (min/day) }\end{array}$ & $\begin{array}{l}1094.8 \pm \\
78.6\end{array}$ & $\begin{array}{l}1082.2 \pm \\
67.9\end{array}$ & $\begin{array}{l}1107.4 \pm \\
88.0\end{array}$ & $\begin{array}{l}1038.3 \pm \\
83.6^{\star \star}\end{array}$ & $\begin{array}{l}1008.4 \pm \\
78.1\end{array}$ & $\begin{array}{l}1065.3 \pm \\
80.7^{\dagger}\end{array}$ \\
\hline $\begin{array}{l}\text { MVPA; } \geqq 3.0 \text { METs } \\
\text { (min/day) }\end{array}$ & $\begin{array}{l}40.7 \pm \\
25.4\end{array}$ & $\begin{array}{l}42.1 \pm \\
28.1\end{array}$ & $\begin{array}{l}39.3 \pm \\
23.1\end{array}$ & $31.2 \pm 17.6$ & $\begin{array}{l}40.7 \pm \\
18.0\end{array}$ & $\begin{array}{l}22.6 \pm \\
12.2^{\dagger+}\end{array}$ \\
\hline \multicolumn{7}{|c|}{$\begin{array}{l}\text { Means } \pm \text { standard deviations, }{ }^{* *} p<0.01 \text {, vs. Men. }{ }^{\dagger} \mathrm{p}<0.05,{ }^{++} \mathrm{p}<0.01 \text {, vs. non-LS., PA; Physical activity, RSB; } \\
\text { Time spent performing resting to sedentary behavior }(<1.5 \text { METs), MVPA; Time spent performing moderate to } \\
\text { vigorous physical activity ( } \geqq 3 \text { METs). }\end{array}$} \\
\hline
\end{tabular}

Table 3 shows the correlation between the LS tests and daily PA (step/day, MVPA, and RSB) of older men and women. For women, the time spent performing MVPA was significantly correlated with the stand-up test ( $r=0.33 ; p$ $=0.04$ ). Additionally, the KE-WBI in women was significantly correlated with the time spent performing MVPA ( $r=$ $0.40 ; p=0.02)$; however, no significant differences were observed in men.

Table 3

Correlation between daily PA and there LS tests score or KE-WBI in older men and women.

\begin{tabular}{|c|c|c|c|c|}
\hline Daily PA Variables & Stand-up test & Two-step test & GLFS-25 & KE-WBI \\
\hline \multicolumn{5}{|l|}{ Men $(n=40)$} \\
\hline Step count (steps/day) & -0.01 & 0.06 & -0.24 & -0.02 \\
\hline $\mathrm{RSB} ;<1.5 \mathrm{METs}$ (min/day) & -0.07 & -0.31 & 0.24 & 0.10 \\
\hline MVPA; $\geqq 3.0$ METs (min/day) & -0.05 & 0.13 & -0.29 & -0.06 \\
\hline \multicolumn{5}{|l|}{ Women $(n=40)$} \\
\hline Step count (steps/day) & 0.29 & 0.18 & -0.16 & 0.21 \\
\hline $\mathrm{RSB} ;<1.5$ METs (min/day) & -0.26 & -0.14 & 0.01 & -0.13 \\
\hline MVPA; $\geqq 3.0$ METs (min/day) & $0.33^{\star}$ & 0.21 & -0.26 & $0.40 *$ \\
\hline
\end{tabular}

Table 4 shows the results of LRA. Crude OR and adjusted OR with 95\% confidence intervals (CI) represent the strength of the relationships between daily PA and category of LS. In the present analysis, effects of sex difference and age were adjusted. As the results, the category of step count with over 5910.20 was significantly related to lower likelihood of LS compared with the lowest step count category of less than 4052.00 (adjusted OR = 0.16, 95\% $\mathrm{Cl}=0.04-0.66)$. The long time spent with over $47.26 \mathrm{~min} /$ day performing MVPA was also associated with a lower likelihood of LS relative to short time category under $21.11 \mathrm{~min} /$ day (adjusted OR $=0.13,95 \% \mathrm{Cl}=0.03-0.56$ ). On the other hand, the time spent 414.90-474.35 min/day for sitting behavior (1.1-1.4 METs) was related to higher 
likelihood of LS compared with short time category under $383.30 \mathrm{~min} /$ day (adjusted OR $=9.13,95 \% \mathrm{Cl}=1.91$ 43.73). Long time spent for RSB (<1.5 METs) with over $1061.76 \mathrm{~min} /$ day was also associated to likelihood of LS (adjusted $\mathrm{OR}=5.27,95 \% \mathrm{Cl}=1.23-22.68$ ).

Table 4. Relationship between daily PA and LS in older men and women.

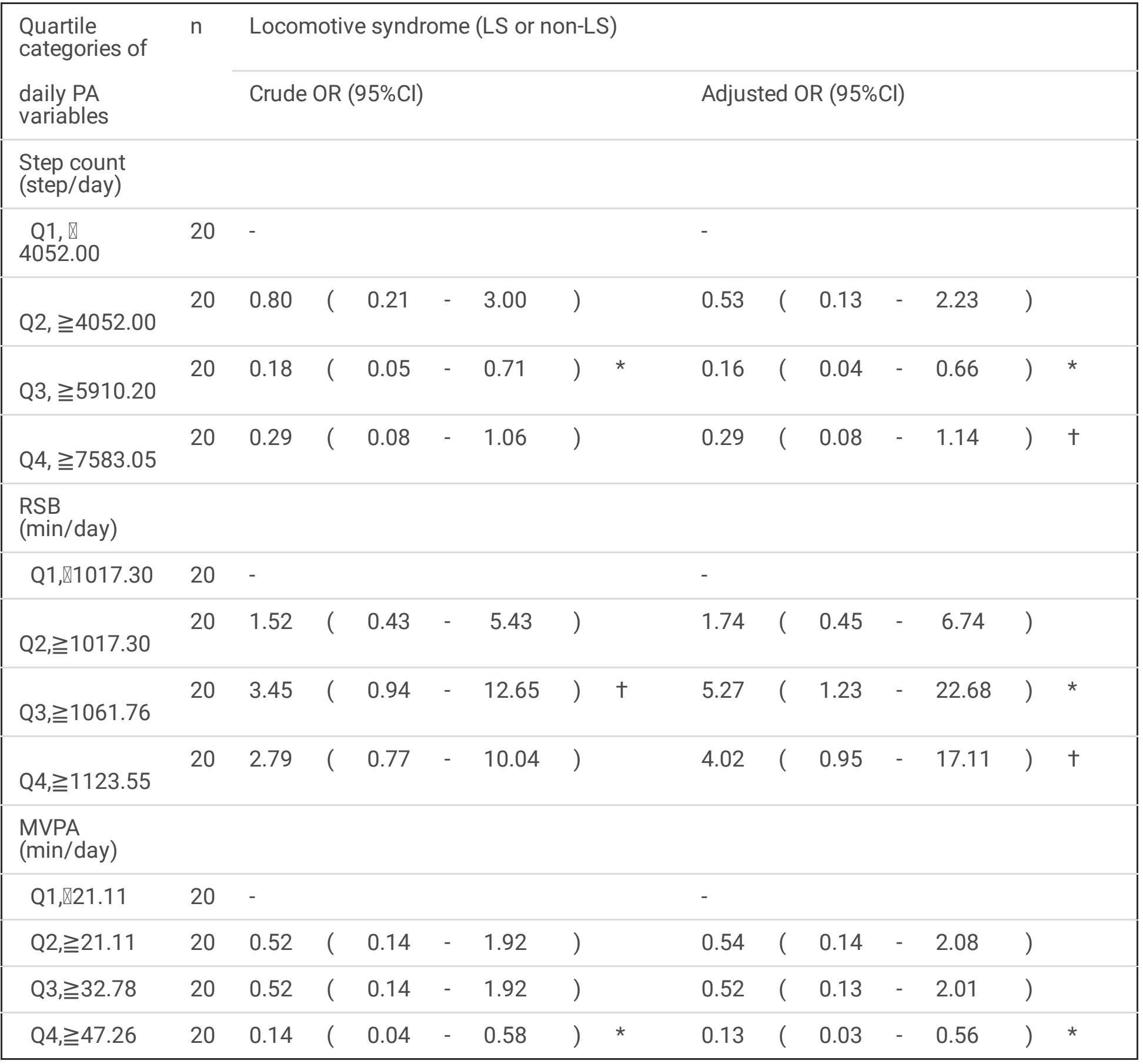

Adjusted OR: Odds ratio adjusted by sex difference and age., †p $₫ 0.10$, *p $₫ 0.05$, vs. Q1., RSB; Time spent performing resting to sedentary behavior (< 1.5 METs), MVPA; Time spent performing moderate to vigorous physical activity ( 3 METs).

\section{Discussion}


The purpose of the present study was to evaluate the association between LS and daily PA in community-dwelling older adults using a three-axis accelerometer. In our study, 41 (men, 20; women, 21) of the 80 participants (51.3\%) met the diagnostic criteria for LS. Older women with LS had lower daily PA (step count and time spent performing MVPA) and relative knee extension strength (weight-bearing index of knee extension) than those without. Logistic regression analyses indicated that LS was associated with step count and the time spent performing RSB $(<1.5$ METs) and MVPA ( $\geqq 3$ METs) using a three-axis accelerometer. We demonstrated that the associations between LS and daily PA were partly dependent on sex differences.

We found that the daily PA of women participants with LS, particularly the step count and time spent performing MVPA, was significantly lower than that of women participants without LS. Aoyagi et al. [20] was showed that lower-extremity function such as gait speed and knee extension torque associated more closely with the daily step count and MVPA for older women, which was suggested that indices of lower-extremity function are significantly greater in physically more active older individuals. Thus, it is suggested that older women with lower levels of daily PA may be at increased risk for LS due to the weakening and loss of musculoskeletal tissues [7]. In fact, previous LS studies demonstrated that 10-m gait speed and muscle strength of leg were significantly lower in the older adults with LS than in those without [21, 22]. Moreover, Nishimura et al. [23] suggested that the frequency of PA between the ages of 25 and 50 years was significantly related to LS, and LS participants who reported no regular exercise habits between the ages of 25 and 50 years had the highest prevalence of LS. Therefore, past exercise habits and current daily physical activities may be associated with the prevention or delay of LS onset, although it cannot prove a cause-and-effect relationship.

Regular PA can delay age-related deterioration of functional capacity [24], independent of the presence of other health problems $[1,25,26]$. Thus, low daily PA reduces mechanical stimulus to the musculoskeletal system, increasing the risk of LS [23]. Furthermore, long periods of inactivity may cause fat accumulation, muscle atrophy, and increased central obesity [27]. In the present study, the body fat percentage of older women was higher among non-LS participants than among LS participants, suggesting that a lower daily PA level and higher obesity-related parameters increase the risk of LS. Since older Japanese women traditionally spend long periods performing lowintensity household tasks [28], purposely an increase in the performing of MVPA is necessary.

It is well known that absolute muscle mass $[14,19]$ and absolute muscle strength $[29,30]$ are generally lower in women than in men. Omori et al. [31] reported that the significant decline in the quadriceps muscle strength was observed in individuals in their sixties and seventies. Additionally, the level of muscle strength of women in their fifties, sixties, and seventies was significantly lower than that of men. To support these points, we found that the KE-WBI of older individuals aged 60-79 years was lesser in women than in men. Moreover, the KE-WBI in women was significantly correlated with the time spent performing MVPA. Therefore, a decrease in the activity and mobility may be observed earlier in women than in men. Although the present study cannot ascertain the causality due to the cross-sectional data, we found that maintaining PA above the intensity of walking ( $\geq 3$ METS) is essential in daily life. In this regard, we recommend that older women practice an interval or progressive walking program, which has been shown to improve leg muscle strength $[32,33]$. These research evidences and exercise protocols will be beneficial in increasing intentional MVPA and preventing LS in older women.

The present study conducted an LRA to examine the relationships between daily PA and category of LS adjusting to sex difference and age. We found that the long time spent performing MVPA using a three-axis accelerometer, with over $47.26 \mathrm{~min} /$ day, was associated with a lower likelihood of LS compared to performing MVPA under 21.11 $\mathrm{min} /$ day. Moreover, a longer period spent on RSB using a three-axis accelerometer with over 1061.76 min/day was 
associated with the likelihood of developing LS. Previous studies report a positive correlation between MVPA and various components of physical fitness and function; in contrast, RSB was negatively associated with the incidence of coronary artery disease, obesity, osteoporosis, and other significant causes of morbidity and mortality in the older adults $[2,10,12]$. It has been suggested that RSB can cause muscle weakness and impaired gait function, resulting in an increased risk of LS and frailty [9]. Although the causal relationship between daily PA and LS risk is unclear, our results suggest an association between daily activity and LS, and the importance of daily PA, including MVPA ( $\geqq 3$ METs).

\section{Limitations}

The present study had several limitations. The sample size of 80 was small compared to previous studies of LS, sarcopenia, and frailty with sample sizes $\geq 100$. However, given the availability of accelerometer-based measures of physical activity and screening tests, our results provided useful and reliable data. Second, the cross-sectional study design made it difficult to examine a causal relationship between daily PA and LS. Therefore, future studies should utilize a prospective cohort design, such as longitudinal study design, to examine the causal relationship between these factors. Third, our participants were limited to relatively healthy older individuals aged 60-79 years who had no history of resistance training, cycling, and other sports activity (i.e., tennis and cycling etc.); therefore, our findings may not be generalizable to the entire Japanese population.

\section{Conclusions}

In conclusion, our data showed that daily moderate to vigorous physical activity (MVPA; $\geqq 3$ METs) and sedentary behavior (RSB; < 1.5 METs) using a three-axis accelerometer were associated with LS in community-dwelling older women, but not in men.

\section{Abbreviations}

LS: locomotive syndrome

PA: physical activities

MVPA: moderate to vigorous physical activity

JOA: Japanese Orthopedic Association

GLFS-25: 25-question geriatric locomotive function scale

QOL: quality of life

ADL: activities of daily living

METs: metabolic equivalents

RSB: resting to sitting behaviors

BMI: body mass index

SMI: skeletal muscle mass index 
Leg-SMI: leg muscle mass index

KE-WBI: knee extension strength/body weight.

SD: standard deviations

LRA: logistic regression analyses

Cl: confidence intervals

OR: Odds ratio

\section{Declarations}

Ethics approval and consent to participate: This study was conducted in accordance with the principles of the Declaration of Helsinki and was approved by the Ethics Committee of the Juntendo University (Approval Number: 26-75). All participants were informed about the content of the study and provided a signed informed consent.

Consent for publication: Not Applicable

Availability of data and materials: All data generated or analyzed during this study are included in this article.

Competing interests: None.

Funding: This research was supported by the Center of Innovation (COI) Program from Japan Science and Technology Agency (JST). The program is one of the main funding programs under the Center of Innovation Science and Technology based Radical Innovation and Entrepreneurship Program (COI STREAM), which was launched in 2013 by the Ministry of Education, Culture, Sports, Science and Technology (MEXT). The funding source had no control over the interpretation, writing, or publication of this work. The corresponding author had full access to all the data in the study and had the final responsibility of the decision to submit for publication.

Authors' contributions: Y.I. designed and performed experiments, analyzed and interpreted data, and prepared the manuscript. H.O., Ta.N, T.Y., To.N., T.K., and P.D. performed the LS tests, habitual daily PA, anthropometrics and body composition, and maximal isometric strengths of leg muscle measurements. M.I., and Y.Y. contributed in the statistical analysis, preparation of the manuscript, and in the discussion. H.K. was responsible for medical examination of the participants. S.M. and H.N. contributed to the manuscript preparation and to the discussion, and they are the guarantors of this work. All the authors reviewed the manuscript. All authors read and approved the final manuscript.

Acknowledgements: We would like to thank Editage (www.editage.jp) for English language editing.

\section{References}

1. Berthelot G, Johnson S, Noirez P, Antero J, Marck A, Desgorces FD, Pifferi F, Carter PA, Spedding M, Manoux AS, et al. The age-performance relationship in the general population and strategies to delay age related decline in performance. Arch Public Health. 2019;77:51.

2. Landi F, Calvani R, Picca A, Tosato M, Martone AM, D'Angelo E, Serafini E, Bernabei R, Marzetti E. Impact of habitual physical activity and type of exercise on physical performance across ages in community-living 
people. PLoS One. 2018;13(1):e0191820.

3. Schwenk M, Mohler J, Wendel C, D'Huyvetter K, Fain M, Taylor-Piliae R, Najafi B. Wearable sensor-based inhome assessment of gait, balance, and physical activity for discrimination of frailty status: baseline results of the Arizona frailty cohort study. Gerontology. 2015;61(3):258-67.

4. Yoshimura N, Oka H, Muraki S, Akune T, Hirabayashi N, Matsuda S, Nojiri T, Hatanaka K, Ishimoto Y, Nagata K, et al. Reference values for hand grip strength, muscle mass, walking time, and one-leg standing time as indices for locomotive syndrome and associated disability: the second survey of the ROAD study. J Orthop Sci. 2011;16(6):768-77.

5. Watanabe D, Yoshida T, Watanabe Y, Yamada Y, Kimura M, Group KS. Objectively measured daily step counts and prevalence of frailty in 3,616 older adults. J Am Geriatr Soc. 2020;68(10):2310-18.

6. Yoshinaga S, Shiomitsu T, Kamohara M, Fujii Y, Chosa E, Tsuruta K. Lifestyle-related signs of locomotive syndrome in the general Japanese population: A cross-sectional study. J Orthop Sci. 2019;24(6):1105-09.

7. Ishibashi H. Locomotive syndrome in Japan. Osteoporos Sarcopenia. 2018;4(3):86-94.

8. Ogata T, Muranaga S, Ishibashi H, Ohe T, Izumida R, Yoshimura N, Iwaya T, Nakamura K. Development of a screening program to assess motor function in the adult population: a cross-sectional observational study. J Orthop Sci. 2015;20(5):888-95.

9. Imagama S, Ando K, Kobayashi K, Machino M, Tanaka S, Morozumi M, Kanbara S, Ito S, Seki T, Ishizuka S, et al. Differences of locomotive syndrome and frailty in community-dwelling middle-aged and elderly people: Pain, osteoarthritis, spinal alignment, body balance, and quality of life. Mod Rheumatol. 2020;30(5):921-29.

10. Bull FC, Al-Ansari SS, Biddle S, Borodulin K, Buman MP, Cardon G, Carty C, Chaput JP, Chastin S, Chou R, et al. World Health Organization 2020 guidelines on physical activity and sedentary behaviour. Br J Sports Med. 2020;54(24):1451-62.

11. LaCroix AZ, Rillamas-Sun E, Buchner D, Evenson KR, Di C, Lee IM, Marshall S, LaMonte MJ, Hunt J, Tinker LF, et al. The objective physical activity and cardiovascular disease health in older women (OPACH) study. BMC Public Health. 2017;17(1):192.

12. Seguin R, Lamonte M, Tinker L, Liu J, Woods N, Michael YL, Bushnell C, Lacroix AZ. Sedentary behavior and physical function decline in older women: findings from the women's health initiative. J Aging Res. 2012;2012:271589.

13. Menai M, van Hees VT, Elbaz A, Kivimaki M, Singh-Manoux A, Sabia S. Accelerometer assessed moderate-tovigorous physical activity and successful ageing: results from the Whitehall II study. Sci Rep. 2017;8:45772.

14. Park H, Park S, Shephard RJ, Aoyagi Y. Yearlong physical activity and sarcopenia in older adults: the Nakanojo Study. Eur J Appl Physiol. 2010;109(5):953-61.

15. Park H, Togo F, Watanabe E, Yasunaga A, Park S, Shephard RJ, Aoyagi Y. Relationship of bone health to yearlong physical activity in older Japanese adults: cross-sectional data from the Nakanojo Study. Osteoporos Int. 2007;18(3):285-93.

16. Seichi A, Hoshino Y, Doi T, Akai M, Tobimatsu Y, Iwaya T. Development of a screening tool for risk of locomotive syndrome in the elderly: the 25-question Geriatric Locomotive Function Scale. J Orthop Sci. 2012;17(2):163-72.

17. Yoshihara T, Ozaki H, Nakagata T, Natsume T, Kitada T, Ishihara Y, Deng P, Osawa T, Ishibashi M, Ishijima M, et al. Effects of a progressive walking program on the risk of developing locomotive syndrome in elderly Japanese people: a single-arm trial. J Phys Ther Sci. 2018;30(9):1180-86.

Page 13/14 
18. Tanaka C, Hikihara Y, Ohkawara K, Tanaka S. Locomotive and non-locomotive activity as determined by triaxial accelerometry and physical fitness in Japanese preschool children. Pediatr Exerc Sci. 2012;24(3):42034.

19. Seino S, Shinkai S, lijima K, Obuchi S, Fujiwara Y, Yoshida H, Kawai H, Nishi M, Murayama H, Taniguchi Y, et al. Reference values and age differences in body composition of community-dwelling older japanese men and women: a pooled analysis of four cohort studies. PLoS One. 2015;10(7):e0131975.

20. Aoyagi Y, Park H, Watanabe E, Park S, Shephard RJ. Habitual physical activity and physical fitness in older Japanese adults: the Nakanojo Study. Gerontology. 2009;55(5):523-31.

21. Imagama S, Hasegawa Y, Ando K, Kobayashi K, Hida T, Ito K, Tsushima M, Nishida Y, Ishiguro N. Staged decrease of physical ability on the locomotive syndrome risk test is related to neuropathic pain, nociceptive pain, shoulder complaints, and quality of life in middle-aged and elderly people - The utility of the locomotive syndrome risk test. Mod Rheumatol. 2017;27(6):1051-56.

22. Yoshihara T, Ozaki H, Nakagata T, Natsume T, Kitada T, Ishihara Y, Sawada S, Ishibashi M, Kobayashi H, Machida S, et al. Association between locomotive syndrome and blood parameters in Japanese middle-aged and elderly individuals: a cross-sectional study. BMC Musculoskelet Disord. 2019;20(1):104.

23. Nishimura A, Ito N, Asanuma K, Akeda K, Ogura T, Sudo A. Do exercise habits during middle age affect locomotive syndrome in old age? Mod Rheumatol. 2018;28(2):334-38.

24. Bickel CS, Cross JM, Bamman MM. Exercise dosing to retain resistance training adaptations in young and older adults. Med Sci Sports Exerc. 2011;43(7):1177-87.

25. Greig CA, Botella J, Young A. The quadriceps strength of healthy elderly people remeasured after eight years. Muscle Nerve. 1993;16(1):6-10.

26. Rantanen T, Era P, Heikkinen E. Physical activity and the changes in maximal isometric strength in men and women from the age of 75 to 80 years. J Am Geriatr Soc. 1997;45(12):1439-45.

27. Muramoto A, Imagama S, Ito Z, Hirano K, Tauchi R, Ishiguro N, Hasegawa Y. Waist circumference is associated with locomotive syndrome in elderly females. J Orthop Sci. 2014;19(4):612-9.

28. Aoyagi Y, Shephard RJ. Sex differences in relationships between habitual physical activity and health in the elderly: practical implications for epidemiologists based on pedometer/accelerometer data from the Nakanojo Study. Arch Gerontol Geriatr. 2013;56(2):327-38.

29. Hagen KB, Dagfinrud H, Moe RH, Østerås N, Kjeken I, Grotle M, Smedslund G. Exercise therapy for bone and muscle health: an overview of systematic reviews. BMC Med. 2012;10(167):1-11.

30. Kent-Braun JA, Ng AV. Specific strength and voluntary muscle activation in young and elderly women and men. J Appl Physiol (1985). 1999;87(1):22-29.

31. Omori G, Koga Y, Tanaka M, Nawata A, Watanabe H, Narumi K, Endoh K. Quadriceps muscle strength and its relationship to radiographic knee osteoarthritis in Japanese elderly. J Orthop Sci. 2013;18(4):536-42.

32. Nemoto K, Gen-no H, Masuki S, Okazaki K, Nose H. Effects of high-intensity interval walking training on physical fitness and blood pressure in middle-aged and older people. Mayo Clin Proc. 2007;82(7):803-11.

33. Ozaki H, Nakagata T, Yoshihara T, Kitada T, Natsume T, Ishihara Y, Deng P, Kobayashi H, Machida S, Naito H. Effects of progressive walking and stair-climbing training program on muscle size and strength of the lower body in untrained older adults. J Sports Sci Med. 2019;19(4):722-28. 